Reynolds, S. (2011). Retromania: Pop Culture's Addiction to Its Own Past. New York: Faber and Faber, Inc.

Routledge, C. (2016). Nostalgia: A Psychological Resource. New York: Taylor \& Francis.

Russian National Corpus (RNC). Retrieved from: https://ruscorpora.ru/new/en/index.html (accessed: 02.11.2020)

Schmid, H.-J. (2000). English Abstract Nouns as Conceptual Shells: From Corpus to Cognition. Berlin, New York: Mouton de Gruyter.

Sibul, V. (2017). Psycholinguistic analysis of lexical-semantic structure in linguistic consciousness of Russian, English and German native speakers. Training, Language and Culture, 1(2), 54-70. Doi: 10.29366/2017tlc.1.2.4

Sierra, J.J., \& McQuitty, S. (2007). Attitudes and Emotions as Determinants of Nostalgia Purchases: An Application of Social Identity Theory. In Journal of Marketing Theory and Practice, 15(2), 99-112.

Wilson, J.L. (2014). Nostalgia: Sanctuary of Meaning. Minneapolis: University of Minnesota Publishing.

УДК 811.131.1

https://doi.org/10.25076/vpl.41.07

С.Н. Орлова

А.А. Конькова

Российский университет дружбы народов

\title{
ЭМОТИВНЫЕ СРЕДСТВА ЯЗЫКА КАК СПОСОБ ВОЗДЕЙСТВИЯ В ИТАЛЬЯНСКОМ И АНГЛИЙСКОМ ПУБЛИЦИСТИЧЕСКОМ ДИСКУРСЕ
}

\footnotetext{
В статье через призму сопоставительного анализа рассматриваются особенности эмотивной функиии языка в публицистическом дискурсе, а также демонстрируется, какие средства языка могут быть использованы для воздействия на читателя. Целью данной статьи является выявление коммуникативно-прагматических аспектов эмотивной функции, реализуемой в рамках итальянского $и$ английского публицистического дискурса. Актуальность данного исследования обусловливается широким распространением языкового
} 
воздействия в современном публииистическом дискурсе ввиду усиления воздействия на читателя. Новизна заключается в том, что в настоящее время коммуникативно-прагматический аспект эмотивной функиии недостаточно раскрыт в публицистическом дискурсе, а также отсутствует достаточное количество современных работ и исследований, связанных с лингвистическим анализом итальянских и английских газет. Исследование проводилось на основе анализа экономических статей из наиболее авторитетных газет Италии La Repubblica, Corriere della Sera, La Stampa, the Guardian $u$ the Telegraph. В работе использовался коммуникативно-прагматический подход $u$ дискурс-анализ $c$ использованием качественных и количественных методов обработки данных. Были исследованы контекст употребления эмотивных средств языка, частота их употребления в итальянских и английских статьях и их способность осуществлять воздействие на читателя. Приводятся доводы о том, что рассматриваемые лингвистические единицы имеют сильное воздействие на сознание. Итоги исследования расширяют познания о способах воздействия публицистического дискурса на читателя, а также о национальном своеобразии итальянской и английской газеты. В своих выводах авторы подчеркивают, что воздействующий потенциал дискурса реализуется с помощью экспрессивности языковых средств.

Ключевые слова: публицистический дискурс, журналистика, анализ дискурса, семантика, прагматический подход, коммуникативно-прагматический аспект, эмотивная функиия, эмотивность, итальянская статья, английская статья, эмотивные средства языка.

УДК 811.131.1

https://doi.org/10.25076/vpl.41.07

S.N. Orlova

A.A. Konkova

RUDN University

\author{
EMOTIVE MEANS OF LANGUAGE AS A WAY OF \\ INFLUENCE IN ITALIAN AND ENGLISH PUBLICISTIC \\ DISCOURSE
}


The article examines the features of the emotive function of language in publicistic discourse, and also demonstrates what language means can be used for the author's influence on the reader. The aim of this paper is to identify the communicative and pragmatic aspects of emotive function implemented in the framework of Italian and English publicistic discourse. The relevance of this study is due to the wide spread of linguistic influence in modern publicistic discourse in order to increase impact on the reader. The novelty lies in the fact that at present the communicative and pragmatic aspect of the emotive function is not sufficiently disclosed in publicistic discourse, and one can also observe an insufficient number of works and research related to the linguistic analysis of Italian and English newspapers. The research was carried out on the basis of an analysis of economic articles from the most authoritative Italian and English newspapers La Repubblica, Corriere della Sera and La Stampa, the Guardian and the Telegraph. The research was conducted on the basis of communicative and pragmatic approach and discourse analysis using qualitative and quantitative methods of data processing. The context of the use of emotive language means, the frequency of their use in Italian and English articles and their ability to influence the reader were investigated. Arguments are given that the linguistic units under consideration have a strong effect on consciousness. The results of the study expand knowledge about the ways in which publicistic discourse affects the reader, as well as about the national identity of the Italian and English newspaper. In conclusion the author emphasizes that the influencing potential of discourse is realised through the expressiveness of linguistic means.

Keywords: publicistic discourse, journalism, discourse analysis, semantics, pragmatic approach, communicative and pragmatic aspect, emotive function, emotivity, Italian article, English article, emotive expressive means

\section{Введение}

Публицистический стиль, являясь одним из функциональных стилей речи, используется для написания статей, отчетов, интервью, очерков и т.д. на различные социальные и политические 
темы. Его основные функции - информационная и воздействующая, которые используются вместе, поскольку автор обращается к публицистическому стилю, когда перед ним стоит задача не только донести информацию до читателя, но тем или иным образом повлиять на него (Malyuga \& Orlova, 2017) . Данная задача осуществляется автором при помощи использования различных лингвистических средств, таких как многозначность слов, словообразовательные ресурсы (авторские неологизмы), эмоционально-экспрессивная лексика (наиболее часто используемые - эпитеты и метафоры), синтаксические средства выражения эмотивности (риторические вопросы и восклицания, повторы, эллипсис, инверсия, парцелляция, антитеза, градация и т.д.) (). Публицистический стиль позволяет убедить читателя в обоснованности выдвинутой инициативы автора и вызвать желаемую реакцию на сказанное при помощи логических рассуждений и эмоциональной напряженности высказывания, демонстрируя те особенности явления, которые можно наиболее эффективно использовать для достижения цели.

Для публицистического стиля характерны как черты научного стиля, то есть логика и последовательность изложения, так и образность и эмоциональность, присущие художественному стилю, поскольку он находится на стыке этих двух стилей.

Публицистический дискурс кажется монологом, но по своей природе он диалогичен. Автор текста стремится не столько проявить свои способности в области языковых навыков и теоретической лингвистики, сколько оказать необходимое воздействие на адресата, незаметно убедить его в чем-то выгодном для самого автора. Следовательно, используемые языковые средства должны успешно воздействовать на представителей всех слоев населения.

Шаховский В.И. придерживался мнения, что эмотивность текста формируется на всех уровнях языка и способствует созданию общей выразительности, которая реализует функцию влияния (Шаховский, 2009). Эмотивность, по его мнению, выступает как лингвистическая категория, означающая способность языковых единиц отражать субъективно индивидуальные переживания определенных эмоций человека.

В рамках данной статьи эмотивность трактуется как 
лингвистическая характеристика сочетания языковых средств, способных произвести эмоциональный эффект, то есть вызвать определенные эмоции у адресата.

Выразительность можно отнести к прагматическим категориям, «это сознательное воздействие на слушателя с точки зрения впечатляющей силы высказывания, выразительности, его эстетической характеристики» (Пиотровская, 1993). Таким образом, выразительность - категория, направленная на адресата, то есть она имеет прагматическое значение.

Эмотивность - это компонент выразительности, отражающий влияние текста на эмоциональную, неинтеллектуальную сферу человеческой психики. Она выступает средством выражения эмоций, чувств, аффектов и настроения адресата, передает его отношение к предметам и явлениям объективной реальности, а также влияет на чувства окружающих.

Шаховский В.И. пишет о взаимосвязи между эмотивной и воздействующей функциями: «Эмотивность является наиболее важным компонентом прагматики языка, поскольку наиболее ярко воплощает в себе ее воздействующую функцию» (Шаховский, 2009, с. 5).

\section{Материалы и методы исследования}

Материалом исследования являются статьи в электронном формате таких известных итальянских и английских газет, как La Repubblica, Corriere della Sera и La Stampa, the Guardian, the Telegraph.

Метод выбора статей обусловлен тем, что в работе было важно представить современную прессу, поэтому выборка статей производилась из изданий 2019-2020 гг., при этом выбранные темы в основном касаются влияния и формирования общественного мнения, поэтому используемый в статьях язык является подходящим для изучения явлений формирования речевого воздействия.

Изначально авторы планировали сосредоточиться только на монотипическом подходе, выбирая темы, посвященные экономике, политике или экологии. Однако при подготовке материала было обнаружено, что выбор статьей разных тематических групп позволяет увидеть то, как функция влияния используется в работе с общественным мнением. 
Таким образом, авторами были отобраны статьи преимущественно на следующие тематики: хроники, политика, наука, технологии.

Авторы использовали следующие методы лингвистических исследований:

- описательный метод, используемый при анализе и изучении форм, структур и процессов на всех уровнях языковой структуры: фонологии, морфологии, синтаксисе, лексике, семантике и прагматике;

- сопоставительный метод сосредоточен на функционировании лингвистической структуры. При использовании этого метода важно соотносить как некоторые элементы языка, так и целые области структуры;

- контекстологический анализ заключается в изучении языковой единицы в контексте. Только принимая во внимание биографический, социально-исторический, литературный, культурный и лингвистический контекст, мы можем полностью судить о содержании текста;

- метод количественного анализа, выявляющий вероятностные статистические данные, а также наиболее частотные, центральные элементы текста. Этот метод важен для определения стилистического признака текста, для изучения отличительных языковых особенностей, характерных тому или иному автору.

\section{Современные итальянские газеты}

Среди самых популярных итальянских газет необходимо выделить такие, как La Repubblica, Corriere della Sera и La Stampa.

Стоит отметить, что с момента зарождения журналистской профессии окончание Второй мировой войны стало деликатным и решающим историческим моментом для итальянской газеты. После устранения фашистской политики в стране необходимо было освободиться от той риторики, которая разрушала выразительность газетных статей, содержание которых касалось только пропаганды и подвергалось цензуре.

Другими словами, произошло то, что газеты перешли от одной проблемы к другой. Статьи были подготовлены в соответствии с правилами традиционной грамматики и совсем не были открыты для нововведений, более того, присутствовали сложные синтаксические конструкции и сложная терминология, которую 
нелегко расшифровать. Только газета Il Giorno попыталась выйти из этой логики, открывшись наиболее популярному стилю. Но это был единичный случай.

В середине 1970-х эта удушающая выразительность начала уходить со страниц газет после тридцати лет безмятежного господства. Изменения произошли с момента основания газеты La Repubblica в 1976 году Эудженио Скальфари, которая сообщала о новинках не только с точки зрения содержания, но также на политическом и лингвистическом уровне. Ему удалось создать модель, которая вышла за рамки назойливой газетной лексики, в пользу коммуникации, далекой от однообразия и неясности смысла. Это новое отношение не осталось в пределах $\mathrm{La}$ Repubblica, a расширилось, находя все больше и больше сообщников с итальянской точки зрения. Направление публицистического стиля в Италии стало смесью общих элементов повседневной речи с культурными и востребованными отсылками. Непосредственно в результатах исследования изложены и обоснованы примеры употребления разговорных фраз в статьях.

В основе изменения высказываний лежали причины иного характера, которые не могли быть связаны только с языком. Станет яснее, если мы обратимся к современному построению газеты La Repubblica: основное внимание уделяется политике по сравнению с новостями, и, помимо представления новостей, газета имеет тенденцию их комментировать. Можно судить о том, что это является прогрессивным шагом авторов, сумевших дать газете еще больше оригинальности и влияния на конкурентном рынке. Таким образом, именно общество, исторический и политический контекст повлияли на формирование языка газет.

В этом смешении балансов время было благоприятным для того, чтобы приветствовать даже языковые метаморфозы, и литературный итальянский язык больше не был тем единственным, чему нужно было следовать и чего нужно было преследовать любой ценой. Таким образом, письменная и устная речь слились в разновидность, которая была признана и обозначена как Italiano neostandard (неостандартный итальянский). Именно из-за этого явления в газетах стали появляться две пересекающиеся линии: открытость речи и желание восстановить письменность. С одной стороны, старые 
стилистические элементы, которые обрекали письмо на неестественное окаменение, отбрасываются, в результате чего в печати появляется более упрощенный синтаксис и лексикон, состоящий из разговорных фраз; с другой стороны, возникает намерение сопровождать публицистический дискурс формами, которые оглашаются в речи, мало контролируемыми конструкциями и прямой речью.

Остановимся подробнее на описании итальянских газет. Как было сказано ранее, La Repubblica была основана в 1976 году Эудженио Скальфари. Из источника с сайта La Repubblica, миссией газеты является создание информированной, активной публики, поощряемой к участию в общественной жизни благодаря лучшему и более глубокому пониманию событий, идей и культуры в Италии и в мире. С этой целью La Repubblica собирает, проверяет, производит и распространяет информацию и другое содержимое, которое служит общественным интересам и помогает поддерживать здоровую коллективную среду. У газеты есть ряд этических принципов, основанных на максимальной прозрачности и ответственности, которым придерживаются ее работники. Основа работы ее журналистов - независимость, отказ от конфликта интересов, внимание к самым спорным точкам зрения, соблюдение прав человека и Конституции Италии. La Repubblica ссылается на ценности европейского единства, это многонациональная международная газета.

La Stampa была основана в Турине 9 февраля 1867 года. Опираясь на 150-летнюю историю, La Stampa стремится интерпретировать ценности светской, беспристрастной и независимой газеты. Как сказал Арриго Леви, «благодаря широте информации газета способствует росту просвещенного и зрелого итальянского общества». Сохраняя свою историческую идентичность как газета, прочно укоренившаяся на Северо-Западе, но имеющая международный охват, La Stampa продвигает ценности европейской культуры, прозрачность и эффективность государственного управления, инновации с чувством ответственности за будущее поколение. Отношения между газетой и ее читателями основаны на доверии к публикациям. В газете четко разделены общие стандарты и ценности, руководящие принципы, касающиеся как журналистской работы, так и всех 
сотрудников газеты.

Corriere della Sera была основана в 1876 году и по традиции является ведущей национальной газетой. Благодаря своему авторитету она веками находится в центре национальной жизни, собирая и анализируя социальную, культурную, политическую и экономическую динамику. Благодаря простому и ясному стилю, эффективному, но умеренному языку и чистой и увлекательной графике, она становится все более современной, доступной и приятной для чтения, не теряя при этом серьезности и объективности. Ежедневно Corriere исчерпывающе удовлетворяет потребности читателя в информации и развлечениях: наряду с текущими событиями, политикой и новостными статьями, редактируемыми самыми известными именами в итальянской и международной журналистике; в ней также размещаются статьи о культуре, развлечениях и досуге.

Теоретические основания

По мере того, как публицистический дискурс и общество меняются, эмоции становятся гораздо более важной динамикой в том, как создаются и потребляются новости. Акцентирование внимания на эмоциях как на ключевом элементе переопределяет классическую идею журналистской объективности - на самом деле это меняет саму идею новостей. Это важно, поскольку публицистический дискурс играет все более ключевую роль в нашей жизни, так как информация, сведения и социальные сети становятся все более повсеместными и авторитетными. Ежедневный поток новостей в Интернете в сочетании с традиционными СМИ стал больше, чем когда-либо прежде. Потребители новостей имеют более широкий доступ к большему количеству журналистских материалов, чем прежде (Russell, 2011).

В настоящее время существует три фактора, побуждающих журналистов использовать эмоции в качестве инструмента. Первый фактор - экономический, поскольку конкуренция в сфере журналистики огромна. Как пишет Крис Петерс в своей работе, новости всегда были эмоциональными - разница сегодня заключается в растущем разнообразии эмоциональных стилей, возросшей приемлемости участия журналистов и в том, что попытки вовлечь аудиторию стали более явными (Peters, 2011). 
Второй фактор заключается в технологии. Существуют четкие доказательства того, что использование эмотивных средств помогает привлечь внимание читателей и продлить взаимодействие с ними. Источник с эмоционально захватывающими изображениями / карикатурами привлекает больше внимания. Текст, написанный на разговорном языке, как правило, увеличивает реакцию у потребителя информации. Следует отметить, что информация все чаще распространяется не через газетные киоски, а посредством социальных сетей. На журналистов возложена ответственность не только за презентацию и представление актуальной информации, но и за публикацию и популяризацию своей работы в сетях. Очень важно убедить людей распространять информацию, а эмоциональное воздействие имеет решающее значение для того, чтобы это произошло.

В-третьих, речь идет о лучшем понимании поведения людей, а также о культурологии и нейропсихологии, стоящих за этим. Понимание того, как люди относятся к новостям как на личном, так и на общественном уровне, жизненно важно для любого, кто хочет привлечь их к тому или иному источнику информации.

С теоретической точки зрения дискурс представляет собой сложное образование, отличающееся рядом элементов. С практической точки зрения дискурс и дискурс-анализ могут предоставить огромное количество лингвистической и экстралингвистической информации, которая может быть использована в различных исследованиях (социология, коммуникативные исследования, психология, экономика и т.д.).

Остановимся на слове «публицистический», чтобы подчеркнуть его современный смысл. Согласно В. Н. Левиной и С. В. Гуськовой, «понятие публицистического текста является синонимом концепции публицистического текста в современной научной парадигме. Существует определенный набор лингвистических критериев, по которым можно определить оригинальность любого текста, в том числе публицистического» (Левина, Гуськова, 2016, http). Фактически критерии развивают идею дискурса как особого текста, который является частью конкретной ситуации, происходящей в данном классе / обществе / культуре.

Понятие публицистического дискурса особенно интересно, 
когда мы анализируем его с точки зрения различных культур. Итальянская культура имеет очень давние и богатые традиции публицистического дискурса, риторика дискурса менялась с течением времени.

Коммуникативные особенности дискурса довольно широки, и они исходят от понятия общения как речевого акта производства текстовой информации. В зависимости от коммуникативной единицы дискурс может различаться и иметь определенные особенности.

Прагматические особенности дискурса можно описать как возможность применять дискурс в реальной жизни, поэтому он должен иметь все необходимые качества, чтобы быть полезным и, таким образом, соотноситься с реальностью и обществом. Лингвист Кобозева И.М. описала прагматический подход как прямое исследование условий речевого общения, поскольку они отражены в языковых выражениях.

Прагматический аспект играет очень важную роль и тесно связан с лингвистическим аспектом формирования текста: единицы текста составляются особым образом, от фонетического и фонологического до лексического уровней, чтобы привлечь аудиторию и поддерживать ее интерес к предмету. Более того, текст должен выполнять очень специфическую роль: недостаточно произвести впечатление, он должен предоставлять медиаинформацию, создавать конкретное видение обсуждаемого предмета, другими словами, иметь влияние на аудиторию. Таким образом, рассматривая единицы медиа-текста, мы можем сосредоточиться на двух аспектах, таких как «аспект привлечения внимания» и «аспект убеждения», которые оба очень важны в анализе данной работы.

\section{Результаты и обсуждение}

Эмотивный язык с точки зрения аргументации - это такой язык, вызывающий определенные эмоции у собеседника (у читателя, если речь идет о бумажном источнике), приводящие его к определенным заключениям. Метафоры или эвфемизмы используются для того, чтобы скрыть определенные понятия. Эвфемизмы в таких случаях принимают точное условное значение. Однако они также могут быть использованы и для сокрытия некоторых аспектов реальности, побуждая собеседника 
сделать вывод, основанный только на частичном представлении ситуации.

Открытость речи, внимание к реализму для достижения объективности, являются важными и центральными в итальянском публицистическом дискурсе. В семидесятые годы появление выразительности в итальянском публицистическом дискурсе принесло с собой прямую речь, которая заняла все более важные части текста. Факт включения прямой речи в текст ограничивает роль писателя, или, по крайней мере, только внешне. Таким образом теряются синтез и переформулирование новостей, а вместе с ними и специфика традиционного публицистического дискурса. От чрезмерного скопления и плохой читаемости, из-за нераспространенной лексики статей начала двадцатого века сегодня мы движемся к противоположному направлению, которое разбавляет и фрагментирует содержание статей сериями вопросов и ответов. Краткость изложения и упрощение текста произвели революцию в выразительности публицистического стиля, изменив традиционные логико-синтаксические связи.

Типов прямой речи, которые можно встретить в газетах, существует два - интервью и цитата. Не будем углубляться в первый тип, однако про цитирование скажем, что это самый распространенный прием в новостных статьях. С помощью цитаты создается впечатление спора, описания и рассказа о каком-то событии, она вводится в косвенную речь, перемежаясь с ней, граница между ними почти размывается. Следующий пример из итальянской газеты демонстрирует это:

«... Marinella si è poi scusato. «La persona ha insistito, gli abbiamo detto che vendiamo online ma poi abbiamo accettato che venisse - si è difeso, cercando di spiegare e giustificare quanto accaduto...»

«...Потом Маринелла извинилась: «Человек настоял, мы сказали ему, что продаем онлайн, но потом согласились, чтобы он пришел - он защищался, пытаясь объяснить и оправдать то, что произошло...»

Читатель должен очень внимательно относиться к непрерывным переходам от цитат к косвенной речи, так как есть риск потери нити повествования. Это также происходит из-за отсутствия передачи сигналов прямой речи, так как обычно глаголы, демонстрирующие это, отсутствуют (такие как сказать, 
добавить, спросить, указать, пояснить и т.д.), а стоят только кавычки. Следующий пример это демонстрирует:

«...«La mia passione per l'astronomia nasce a 22 anni mentre frequentavo la facoltà di Giurisprudenza». Paolo Zampolini ora di anni ne ha 33 e fa l'avvocato, vive a Viterbo e insieme a cinque amici ha fondato il Gruppo astrofili Galileo Galilei a Tarquinia...»

«...«Моя страсть к астрономии родилась в 22 года, когда я учился на юридическом факультете». Паоло Замполини сейчас 33 года, он работает юристом, живет в Витербо и вместе с пятью друзьями основал любительскую группу астрономов Galileo Galilei в Тарквинии...»

Писатели могут сократить цитату или дополнить ее своим мнением, представить и освятить ее в наиболее благоприятном для них положении. Таким образом, прямая речь является одним из эффективных способов воздействия на читателя.

Далее приведены примеры прямой речи из газеты The Guardian:

"...The driver of our car, a white woman, looked at the lone black man surrounded by police officers with their guns drawn and said: "It's good they've got so many on him. You never know what they'll do."”

«...Водитель нашей машины, белая женщина, посмотрела на чернокожего мужчину, окруженного сотрудниками полищии $c$ оружием, и сказала: "Хорошо, что у них так много оружия. Никогда не знаешь, что сделают эти чернокожие."”

Следующий пример:

«...A party spokesman said: "All reportable donations to the Conservative party are correctly declared to the Electoral Commission, published by them and comply fully with the law..."”

«...Пресс-секретарь партии сказал: "Все отчитываемые пожертвования в консервативную партию правильно объявлены в избирательной комиссии, опубликованной ею и полностью соответствуют закону..."”

Существует два ведущих способа использования эмотивных средств: слова могут использоваться для возбуждения эмоций, посредством представления ситуации, отличной от реальности; или термины, обычно связанные с отрицательным или положительным представлением ситуации, могут употребляться для изменения оценки уже известной ситуации. Это различие 
имеет решающее значение для понимания связи между значением слова и эмоциями, которые оно вызывает.

Лексические средства находятся на главенствующей позиции среди эмотивных средств языка. На данный момент выделяется следующая тенденция в изучении лексических средств: а) исследование отдельных эмотивных лексем; б) изучение лексикосемантических групп эмотивной лексики; в) исследование синонимов / антонимов, относящихся к эмотивным средствам; г) исследование роли метафоры в смысловой репрезентации эмоций.

Кажется, что разговорные выражения представляют собой наиболее существенный лексический пласт публицистического дискурса, в соответствии с тенденцией употреблять простой язык, который используется в повседневной жизни читателей, хотя и с должными оговорками. В большом количестве разговорных фраз Бономи признает языковой выбор, который частично является преднамеренным, а частично - признаком пренебрежения при составлении текстов. Однако следует иметь в виду, что выбор наиболее употребительного слова вместо более сложных его синонимов может соответствовать поиску определенной выразительности, из чего можно заключить, что разговорные фразы - потенциально эмотивные. Их можно назвать «ключевыми» компонентами, «фундаментальными частями», находящимися в рамках суждения, а также всего текста (Bonomi, 2016).

Было проанализировано наличие разговорной лексики в статьях итальянских газет. Получился следующий набор слов, который мы выбрали для нашего исследования:

- именные и словесные фразы, наделенные большой выразительностью, как vederci chiaro / ясно видеть, canta vittoria / поет победу, picchia/picchiano duro / бьет/бьют сильно, montagna di quattrini / гора денег;

- smetterla / прекратить;

- stavolta / на этот раз;

- infatti / на самом деле

- strombazza / шумно рекламирует;

- perdere la faccia / потерять лицо (потерять честь).

Единственное уточнение, которое мы можем сделать, это то, что есть более распространенные выражения и без определенной 
функции, такие как smetterla, stavolta, vederci chiaro, которые отличаются от других разговорных фраз, принадлежащих к определенным областям, таким как girare / переключать (компьютерную программу) в отношении того, как это работает.

В следующем примере, взятом из газеты La Stampa, разберем разговорную фразу perdere la faccia.

"...Una maniera per non "perdere la faccia», letteralmente, in tempi di pandemia ...»

«...Способ не «потерять лицо» буквально во время пандемии ...»

«Потерять лицо (потерять честь)» - типичное словосочетание в разговорной речи итальянского языка, используемое для описания ситуации, в которой человек теряет репутацию, престиж или достоинство. То есть, выражение «потерять лицо» означает, что человек больше не имеет смелости показать, какой он есть, из-за обстоятельств, в которых была потеряна его честь. Однако в данной ситуации фраза теряет свой первоначальный смысл; автор статьи намеренно использует фразу «потерять лицо», чтобы рассказать читателю про изобретение новой маски во время пандемии, изображающей лицо носящего ее. Таким образом, такая неоднозначная фраза привлекает внимание читателя и заинтересовывает его в прочтении статьи.

В данном примере присутствует слово, используемое в разговорной речи, infatti / на самом деле.

"...Il fedele e affezionato compratore infatti è stato sanzionato perché si trovava al di fuori dal proprio Comune di residenza...»

«...На верного и преданного покупателя на самом деле были наложены санкиии, потому что он находился за пределами своего муниципального проживания...»

Из этой же статьи La Stampa мы видим еще одно разговорное слово stavolta / на этот раз.

«...Abbiamo sbagliato, io cerco sempre di essere corretto ma stavolta abbiamo avuto una debolezza ...»

«...Мы ошиблись, я всегда стараюсь поступать правильно, но на этот раз на нас была минутная слабость...»

Stavolta - наречие, которое встречается в письменной форме с 1950 года и употребляется в основном в разговорной речи, происходит от фразы «questa volta», которая подверглась аферезе 
(фонетическое явление, при котором происходит выпадение начального звука в слове), и два элемента слились в один. Такой же процесс произошел и с другими наречиями времени, такими как «stamattina / сегодня утром» и «stanotte / сегодня вечером», широкое распространение и использование которых, в особенности в письменной форме, не позволяет задуматься, что они являются разговорными. Неудивительно, что у слова stavolta / на этот раз такое большое количество случаев употребления, которые уже проникли как в устную, так и в письменную речь.

Мы не можем отрицать того, что, исключая список выбранных слов, в газетах широко распространена блестящая выразительность и использование только стандартной лексики, более или менее подчеркнутой в соответствии с редакционными направлениями газет. Отходя от нашего исследования, следует сделать некоторые пояснения: выразительность языка превалирует в газетах во всех ее сферах, проявляя себя в качестве инструмента для сближения автора с читателем, а также в соответствии с тенденцией к упрощению информации и желанием привлечь читателя к покупке газет в период распространения информации по большей части в социальных сетях. С другой стороны, часто встречаются нецензурные выражения в газетах, вдохновленных ярко выраженной и радикальной политической линией, например, «Fatto Quotidiano» или «Libero» нередко используют экспрессивный и оскорбительный язык (Bonomi, 2016). Хотя мы не можем сделать оценочное суждение, с другой стороны, следует отметить, что желание произвести впечатление на отличительную модель в письменной форме часто приводит к созданию текста, в котором игнорируется информативный аспект, а все усилия автора сосредоточены на попытке «ослепить читателя». Однако из нашего анализа выявляется довольно ограниченный тип такой разновидности.

В ходе нашего исследования также были проанализированы английские статьи на наличие разговорной лексики и проведен сравнительный анализ.

Далее пример из газеты The Telegraph:

«...Feels pretty mисh like a Cold War to me...» «...По ошущениям для меня очень даже как холодная война..»

Фраза pretty much является неофициальной, однако мы видим 
ее в статье на политическую тематику.

Далее пример неформального слова freak:

«...This was not a freak policy of Dave and George...» «... Эma политика Дейва и Джорджа не была странной...»

В ходе сравнения итальянского и английского публицистического дискурса было выяснено, в обоих языках используются разговорные фразы и выражения.

Зачастую в газетах встречаются политические и журналистские термины, благодаря которым у читателя складывается определенное впечатление и умозаключение (Sokolova, 2020). Представители той или иной культуры как правило понимают значения большинства политических и социально-политических терминов.

Мы также подчеркиваем потенциальную роль коммуникативной компетенции и мотивов использования политического выражения в публицистическом дискурсе. Коммуникативная компетентность определяется как воспринимаемая эффективность и целесообразность, которые, по мнению людей, связаны с необходимостью достижения целей межличностного общения (Canary, Spitzberg, 1987). В контексте цифровых медиа восприятие компетенции может отличаться по мере изменения коммуникативных практик людей (Spitzberg, 2006).

Мы понимаем выражение политических взглядов как сообщение, которое представляет определенное мнение о текущих событиях или политических процессах, или распространяет информацию, имеющую отношение к интерпретации этих событий или процессов. Политическое выражение - это политическое поведение, с которым также связаны факторы и динамика межличностного общения. В этом смысле представления людей о том, насколько они компетентны в своих межличностных коммуникационных взаимодействиях также имеют значение, при изучении выражения мнений прослеживаются в публицистических статьях.

По направленности эмотивности общественно-политическую лексику можно разделить на три группы:

1) имеющую позитивную оценку;

2) имеющую отрицательную оценку; 
3) имеющую нейтральную оценку.

В следующем отрывке из статьи можно увидеть журналистский термин spaccarsi.

«...Ora su Mario Draghi $i$ gruppi pentastellati rischiano di spaccarsi...»

«...Tеперь на Марио Драги группь 5 звезд (итальянская политическая партия «Движение пяти звезд») находятся под угрозой разделения...»

Изначально термин имеет значение что-то сломать, действуя намеренно и используя физическую силу, однако в последнее время имеет также значение журналистское и политическое, а именно создать внутри партии, движения или собрания разделение, восприимчивое к серьезным последствиям. Таким образом, используя негативооценочное слово, автор вызывает определенные эмоции у читателя.

Ниже приведен отрывок из статьи, взятой из газеты La Stampa (24 февраля 2020 г.), где было рассмотрено такое выразительное средство синтаксиса как риторический вопрос.

«Ma Quanta gente dovete sfamare con tutto questo cibo?...»

«Но сколько людей нужно накормить всей этой едой?...» (La Stampa, Cronicles)

Риторические фигуры являются имитацией диалогических отношений в монологической речи автора, представляющей собой обмен репликами с аудиторией. Одна из особенностей риторических фигур - использование вопросительной и восклицательной интонации, за счет чего высказывание приобретает эмоциональную окраску.

С помощью вопросительной конструкции кажется, что автор создает эффект диалога, но на самом деле он снижает категоричность побудительного высказывания. Коммуникативное намерение можно определить в желании автора убедить адресата в том, что не было необходимости покупать товары в огромных количествах и создавать ажиотаж в супермаркетах.

Следующий фрагмент статьи взят из газеты Corriere della Sera, где также продемонстрирован риторический вопрос. Статья посвящена эволюционному развитию человека, отличиям в стадиях развития человека разумного от млекопитающих, в особенности в сравнении с шимпанзе. 
"...ma se guardiamo la testa rotonda, gli occhioni e la faccia piatta di un cucciolo di scimpanzé ci sembrerà umano in un modo quasi inquietante. Siamo scimmie bambine, dunque fragili. Ma come ̀̀ possibile? Non ha senso, dovremmo già essere estinti...»

«...но, если мы посмотрим на круглую голову, большие глаза и плоское лицо детеныша иимпанзе, оно почти жутким образом будет казаться человеческим. $\mathrm{Mbl}$ - обезьяны детеныши, поэтому мы уязвимы. Как это возможно? В этом нет смысла, тогда мы должны были бы вымереть...»

Автор статьи употребляет риторический вопрос для того, чтобы направить внимание читателя на ранее сказанную фразу, подчеркнуть ее значимость и с помощью вопроса задержать внимание читателя на проблеме. Кроме того, мы встречаем стилистически окрашенную лексику в данном отрывке, in un modo quasi inquietante / почти жутким образом, что делает акцент на усилении схожести именно ребенка шимпанзе с человеком, а также внимание читателя сосредотачивается на парадоксальности того, что люди до сих пор живы, несмотря на то что лицо человека больше схоже с лицом детеныша обезьяны, чем взрослой особи.

Нередко автор начинает статью именно с риторического вопроса, чтобы сильнее приковать читателя к той или иной проблеме. При использовании вопроса в начале статьи, у автора больше шансов на то, что читатель продолжит ее читать.

Далее начало статьи из газеты the Telegraph:

"What is so funny about patriotism?...»

"Что такого смешного в патриотизме? ...»

Следующий пример взят из газеты the Guardian:

"...Some may want to call the events of June 2020 a "racial reckoning", but in a country in which there was a civil war and a civil rights movement 100 years apart, at some point it would be useful to ask how long a reckoning need take. When, if ever, will we have reckoned?»

«...Некоторые назовут события в июне 2020 года «расовой расплатой», однако в стране, в которой была гражданская война и движение за гражданские права 100 лет назад, было бы полезно спросить в какой-то момент, как долго потребуется расплата. Когда, если вообще когда-то, мы рассчитаемся?»

Таким образом, употребление риторического вопроса в статье 
усиливает эмоциональность, выразительность и яркость речи, возбуждает у читателя интерес к тому или иному явлению, задерживает внимание читателя.

Обращаясь вновь к итальянским газетам, следует упомянуть такое достаточно частое явление, как заимствования. На данный момент в итальянских газетах наблюдается тенденция использования писателями английских терминов, фраз и слов для усиления значения написанного или сказанного. С психологической точки зрения использование заимствований, как кажется, придает итальянскому языку авторитет и статус. Именно английский язык выступает в качестве предпочитаемого языкадонора итальянцев и показывает то, что современные писатели готовы к повсеместному заимствованию иностранных слов в свой родной.

Эта колоритная и выразительная техника называется переключением кода (switching of codes). Переход с одного языка на другой всегда можно отметить на границах предложений, а в особых условиях языкового контакта билингвы не могут соотнести все предложение (иногда фразу) с точки зрения грамматики к тому или иному языку.

Далее дан отрывок статьи из газеты Corriere Della Sera / Coronovirus News из раздела Новости.

«...A essere pericolosi sono dunque più che altro "superspreading events», ovvero eventi di supercontagio. Sebbene qualsiasi persona infetta possa diffondere il virus ci sono circostanze in cui i contagi possono diventare incontrollabili...»

«...Следовательно, быть опасным - это больше, чем что-либо еще, "сверхраспространение событий» или события сверхзаражения. Хотя любой инфицированный человек может распространить вирус, существуют обстоятельства, при которых инфекиии могут стать неконтролируемыми...»

Так, можно сделать вывод, что современные авторы регулярно обращаются к иностранным словам при написании статей для ведущих итальянских газет. Необходимо упомянуть, что авторы прибегают не только к иностранным словам из английского, но и из других языков. С точки зрения выражения категории эмотивности прежде всего именно заимствования употребляются для придания достоверности повествуемого, для передачи 
образности и выразительности фразы.

\section{Выводы}

В результате проведенного исследования можно заключить, что эмотивные средства в итальянском и английском публицистическом дискурсе используются для воздействия на читателя, для передачи отношения автора к обсуждаемой проблеме. Анализ материала показал, что самая выразительная риторическая фигура $\mathrm{c}$ наибольшей частотой упоминаний в итальянском, а также английском публицистическом дискурсе это риторический вопрос. Он подчеркивает эмоциональную функцию и представляет реакцию автора на сообщение, содержащееся в предыдущих отрывках текста. Риторический вопрос направляет внимание читателя на ранее сказанную фразу, подчеркивает еe значимость; с помощью вопроса автор задерживает внимание читателя на описываемой проблеме.

Анализ использования в публикациях цитат показал, что цитирование - наиболее распространенное явление в английских статьях, нежели в итальянских, в особенности широко используется в разделах «бизнес» и «политика».

Достаточно заметной тенденцией в итальянских статьях является использование заимствований, в частности английских терминов, фраз и слов, которые вводятся для усиления значения написанного. С психологической точки зрения благодаря заимствованиям итальянский язык приобретает авторитет и статус. Как показал анализ, в английских статьях используется минимальное количество заимствований или не используется вообще, что обусловливается тем, что английский - язык мирового масштаба, на котором говорят во многих странах.

Кроме того, была выявлена большая частота употреблений разговорной лексики в статьях. Выбор наиболее употребительного слова вместо более сложного аналога может соответствовать поиску определенной выразительности, из чего можно сделать вывод, что разговорные фразы - потенциально эмотивные. В ходе сравнения итальянского и английского публицистического дискурса было выявлено регулярное использование разговорных фраз и выражений в обоих исследуемых языках.

Таким образом, можно прийти к заключению, что как в современной итальянской прессе, так и в английской функция 
передачи информации и функция влияния являются главными, порой невозможно определить, какая из них превалирует. Когда автор изобретателен и прибегает к творческому использованию правильных лексических средств, его публикации способны оказать особое влияние на читателя.

\section{Литература}

1. Иванова И. П. Стилевые характеристики публицистического дискурса // Ученые записки Тамбовского отделения РоСМУ, 2014. Режим доступа: https://cyberleninka.ru/article/n/stilevyeharakteristiki-publitsisticheskogo-diskursa (дата обращения 16.01.2021)

2. Комлева Е. В. Апеллятивность в языке и речи (на материале современного немецкого языка) // Вестник ЛГУ им. А.С. Пушкина, 2008. №5 (19). С. 152-164.

3. Малюга Е.Н., Попова К.В. Лингвопрагматика речевых стратегий в социальной рекламе // Вестник Московского государственного областного университета (электронный журнал), 2018. №4. С. 231-241. Режим доступа: www.evestnikmgou.ru. (дата обращения 16.01.2021)

4. Малюга Е.Н. Функции юмора в англоязычном экономическом дискурсе // Вестник Московского университета. Серия 9. Филология. 2020. № 6. С. 31-43.

5. Никонова Е.А. Специфика реализации воздействующей и манипуляторной функции в политическом англоязычном эссе // Вестник Томского государственного педагогического университетаю 2018. №7 (196). С. 9-14.

6. Пиотровская Л. А. Эмотивность как языковая категория // Вестн. С.-Петербургского ун-та. Сер. история языкознания, 1993. Вып. 2. №9. С. 41-47.

7. Санжеева Л.Ц., Очиров Т.Е. Манипулятивная функция политических реалий в публицистическом дискурсе // Вестник БГУ. Язык, литература, культура, 2017. №2. Режим доступа: https://cyberleninka.ru/article/n/manipulyativnayafunktsiya-politicheskih-realiy-v-publitsisticheskom-diskurse (дата обращения 16.01.2021) 
8. Солганик Г.Я. О структуре и важнейших параметрах публицистической речи (языка СМИ) // Язык современной публицистики: сб. ст. М.: Флинта: Наука, 2007. С. 13-31.

9. Урина Н. В. Очерки истории итальянской журналистики. М.: Фак. журн. МГУ, 2018. Режим доступа: http://www.journ.msu.ru/upload/iblock/17c/17c8361580a8aa9a2c5 9b4ff89c8d5e0.pdf (дата обращения 16.01.2021)

10. Черданцева Т.З. Очерки по лексикологии итальянского языка. Москва: ЛКИ, 2007.

11. Шаховский В.И. Категоризация эмоций в лексикосемантической системе языка. М.: Либроком, 2009.

12. Шаховский В.И. Типы языковых значений эмотивной лексики // Вопросы языкознания, 1994. №1. С. 20-26.

13. Bonomi I., L'italiano giornalistico. Dall'inizio del '900 ai quotidiani online, Firenze, Franco Cesati Editore, 2002.

14. Bonomi I., Maraschio N., L'Italiano. Conoscere e usare una lingua formidabile. Giornali, radio e tv: la lingua dei media, Roma, Gruppo Editoriale L'Espresso, 2016.

15. Canary D.J., Spitzberg B.H. Appropriateness and effectiveness perceptions of conflict strategies. Human Communication Research, 1987. №14. Pp. 93-120.

16. Cortelazzo M. L'Italiano giornalistico. Università degli Studi di Padova, Padova, 2016. Режим доступа: http://tesi.cab.unipd.it/57096/1/Giulia_De_Blasi_2017.pdf (дата обращения 16.01.2021)

17. Levina V.N., Guskova S.V. Publicistic Text in Modern Media Discourse and its Impact on the Audience // Indian Journal of Science and Technology, 2016. Vol. 9 (44). Режим доступа: www.indjst.org (дата обращения 16.01.2021)

18. Malyuga E. N., Tomalin B. Communicative strategies and tactics of speech manipulation in intercultural business discourse. Training, Language and Culture, 2017. - №1. - Pp. 28-48. Retrieved from https://rudn.tlcjournal.org/archive/1(1)/1(1)-02.pdf (дата обращения 16.01.2021)

19. Malyuga E.N., Orlova S.N. Linguistic pragmatics of intercultural professional and business communication. Springer, 2017. 
20. Peters C. Emotion aside or emotional side? Crafting an 'experience of involvement' in the news. Journalism. 2011. №12(3). Pp. 297-316. doi:10.1177/1464884910388224

21. Russell A. Networked: A contemporary history of news in transition. Cambridge, UK: Polity Press, 2011.

22. Sokolova A. G. Anglicisms and loanwords: The contribution of English exemplified by contemporary Italian tourist terminology // Training, Language and Cultureю 2020. №4(2). Pp.21-30. Doi: 10.22363/2521-442X-2020-4-2-21-30

23. Spitzberg B.H. Preliminary development of a model and measure of computer-mediated communication (CMC) competence. Journal of Computer-Mediated Communication, 2016. №11. Pp. 629-666.

\section{References}

Bonomi, I. (2002). L'italiano giornalistico. Dall'inizio del '900 ai quotidiani online [Journalistic Italian. From the early 1900s to online newspapers]. Firenze, Franco Cesati Editore.

Bonomi, I., \& Maraschio, N. (2016). L'Italiano. Conoscere e usare una lingua formidabile. Giornali, radio e tv: la lingua dei media, [Italian. Know and use a formidable language. Newspapers, radio and TV: the language of the media]. Rome, Gruppo Editoriale L'Espresso.

Canary, D.J., \& Spitzberg, B.H. (1987). Appropriateness and effectiveness perceptions of conflict strategies. Human Communication Research, 14, 93-120.

Cortelazzo, M. (2016). L'Italiano giornalistico [Journalistic Italian]. Università degli Studi di Padova, Padova. Retrieved from http://tesi.cab.unipd.it/57096/1/Giulia_De_Blasi_2017.pdf

Ivanova, I.P. (2014). Stilevye harakteristiki publicisticheskogo diskursa [Style peculiarities of publicity discourse]. Uchenye zapiski Tambovskogo otdeleniya RoSMU. Retrieved from https://cyberleninka.ru/article/n/stilevye-harakteristikipublitsisticheskogo-diskursa

Komleva, E.V. (2008). Apellyativnost' v yazyke i rechi (na materiale sovremennogo nemeckogo yazyka) [Appeal in Language and Speech (on the basis of a contemporary German language)]. Vestnik LGU im. A.S. Pushkina, 5 (19), 152-164. 
Levina, V.N., \& Guskova, S.V. (2016). Publicistic Text in Modern Media Discourse and its Impact on the Audience. Indian Journal of Science and Technology, 9 (44). Retrieved from: www.indjst.org (accessed 16.01.2021)

Malyuga, E.N., \& Popova, K.V. (2018). Lingvopragmatika rechevyh strategij $\mathrm{v}$ social'noj reklame [Linguo-pragmatics of speech strategies and tactics in social advertising]. Vestnik Moskovskogo gosudarstvennogo oblastnogo universiteta (elektronnyj zhurnal), 4, 231-241. Retrieved from www.evestnik-mgou.ru. (accessed 16.01.2021)

Malyuga, E.N. (2020). Funktsii iumora v angloiazychnom ekonomicheskom diskurse [Functions of humor in the Englishlanguage economic discourse]. Bulletin of Moscow University. Series 9. Philology, 6, 31-43.

Malyuga, E.N., \& Tomalin, B. (2017). Communicative strategies and tactics of speech manipulation in intercultural business discourse. Training language and culture, 1, 28-48. Retrieved from https://rudn.tlcjournal.org/archive/1(1)/1(1)-02.pdf (accessed 16.01.2021)

Malyuga, E.N., \& Orlova, S.N. (2017). Linguistic pragmatics of intercultural professional and business communication. Springer.

Nikonova, E. A. (2018). Specifika realizacii vozdejstvuyushchej i manipulyatornoj funkcii $\mathrm{v}$ politicheskom angloyazychnom esse [Specifics of the implementation of the influencing and manipulative function in the political English language essay]. Vestnik Tomskogo gosudarstvennogo pedagogicheskogo universiteta, 7 (196), 9-14.

Peters, C. (2011). Emotion aside or emotional side? Crafting an "experience of involvement" in the news. Journalism, 12(3), 297316.

Piotrovskaya, L. A. (1993). Emotivnost' kak yazykovaya kategoriya [Emotivity as a linguistic category]. Vestnik SanktPeterburgskogo universiteta. Seriya Istoriya yazykoznaniya №2, 9, $41-47$.

Russell, A. (2011). Networked: A contemporary history of news in transition. Cambridge, UK: Polity Press.

Sanzheeva, L.C., \& Ochirov, T.E. (2017). Manipulyativnaya funkciya politicheskih realij $\mathrm{v}$ publicisticheskom diskurse [Manipulative 
function of political realities in publicistic discourse]. Vestnik $B G U$. Yazyk, literatura, kul'tura, 2. Retrieved from https://cyberleninka.ru/article/n/manipulyativnaya-funktsiyapoliticheskih-realiy-v-publitsisticheskom-diskurse. (accessed 16.01.2021)

Sokolova, A.G. (2020). Anglicisms and loanwords: The contribution of English exemplified by contemporary Italian tourist terminology. Training, Language and Culture, 4(2), 21-30. Doi: 10.22363/2521-442X-2020-4-2-21-30

Solganik, G.Ya. (2007). O strukture $i$ vazhnejshih parametrah publicisticheskoj rechi (yazyka SMI) [The structure and the most important parameters of publicistic speech (media language)]. Yazyk sovremennoj publicistiki. M.: Flinta: Nauka.

Urina, N. V. (2018). Ocherki istorii ital'yanskoj zhurnalistiki [Essays on the history of Italian journalism]. M.: Fak. zhurn. MGU. Retrieved from http://www.journ.msu.ru/upload/iblock/17c/17c8361580a8aa9a2c5 9b4ff89c8d5e0.pdf (accessed 16.01.2021)

Cherdanceva, T. Z. (2007). Ocherki po leksikologii ital'yanskogo yazyka [Essays on the lexicology of the Italian language]. Moscow: LKI.

Shahovskij, V.I. (2009). Kategorizaciya emocij $v$ leksikosemanticheskoj sisteme yazyka [Categorization of emotions in the lexical-semantic system of the language]. M.: Librokom.

Shahovskij, V.I. (1994). Tipy yazykovyh znachenij emotivnoj leksiki [Types of linguistic meanings of emotive language]. Voprosy yazykoznaniya, 1, 20 - 26.

Spitzberg, B. H. (2006). Preliminary development of a model and measure of computer-mediated communication (CMC) competence. Journal of Computer-Mediated Communication, 11, 629-666.

Russell, A. (2011). Networked: A contemporary history of news in transition. Cambridge, UK: Polity Press. 